\title{
Gas-particle partitioning and hydrolysis of organic nitrates formed from the oxidation of $\alpha$-pinene in environmental chamber experiments
}

\author{
Jeffrey K. Bean and Lea Hildebrandt Ruiz \\ McKetta Department of Chemical Engineering, The University of Texas at Austin, Austin, Texas, USA \\ Correspondence to: Lea Hildebrandt Ruiz (lhr@che.utexas.edu)
}

Received: 27 June 2015 - Published in Atmos. Chem. Phys. Discuss.: 31 July 2015

Revised: 3 February 2016 - Accepted: 9 February 2016 - Published: 25 February 2016

\begin{abstract}
Gas-particle partitioning and hydrolysis of organic nitrates $(\mathrm{ON})$ influences their role as sinks and sources of $\mathrm{NO}_{x}$ and their effects on the formation of tropospheric ozone and organic aerosol (OA). In this work, organic nitrates were formed from the photo-oxidation of $\alpha$-pinene in environmental chamber experiments under different conditions. Particle-phase ON hydrolysis rates, consistent with observed ON decay, exhibited a nonlinear dependence on relative humidity (RH): an ON decay rate of 2 day $^{-1}$ was observed when the RH ranged between 20 and $60 \%$, and no significant ON decay was observed at RH lower than $20 \%$. In experiments when the highest observed $\mathrm{RH}$ exceeded the deliquescence $\mathrm{RH}$ of the ammonium sulfate seed aerosol, the particle-phase ON decay rate was as high as 7 day $^{-1}$ and more variable. The ON gas-particle partitioning was dependent on total OA concentration and temperature, consistent with absorptive partitioning theory. In a volatility basis set, the ON partitioning was consistent with mass fractions of [0 $\left.\begin{array}{lll}0.11 & 0.03 & 0.86\end{array}\right]$ at saturation mass concentrations $\left(C^{*}\right)$ of [1 $101001000] \mu \mathrm{g} \mathrm{m}^{-3}$.
\end{abstract}

\section{Introduction}

Organic nitrates $(\mathrm{ON})$ play an important role in atmospheric chemistry as they can act as sinks and sources of $\mathrm{NO}_{x}$ $\left(\mathrm{NO}+\mathrm{NO}_{2}\right)$ and thereby affect the formation of tropospheric ozone and organic aerosol. The sink reaction - addition of NO to a peroxy radical ( $\mathrm{R}-\mathrm{O}-\mathrm{O} \cdot)$ to form an organic nitrate $\left(\mathrm{R}-\mathrm{O}-\mathrm{NO}_{2}\right)$ - breaks the $\cdot \mathrm{OH}$-initiated oxidation cycle and reduces the formation of ozone (Seinfeld and Pan- dis, 2006). Most $\mathrm{R}-\mathrm{O}-\mathrm{NO}_{2}$ molecules are semivolatile and are therefore expected to partition between the gas and particle phases. They can be transported in either phase and can become a source of $\mathrm{NO}_{x}$ when they are photolyzed or oxidized, contributing to the regional nature of $\mathrm{NO}_{x}$ pollution. Attempts to implement organic nitrate decomposition reactions in a chemical transport model, which did not account for gas-particle partitioning of organic nitrates, resulted in overprediction of $\mathrm{NO}_{x}$ and ozone concentrations (Yarwood et al., 2012), consistent with an overestimate of the strength of organic nitrates as $\mathrm{NO}_{x}$ sources.

Recent studies have suggested that organic nitrates in the condensed phase may undergo hydrolysis, leading to the formation of $\mathrm{HNO}_{3}$ (Day et al., 2010; Darer et al., 2011; Hu et al., 2011; Liu et al., 2012; Browne et al., 2013; Jacobs et al., 2014; Rindelaub et al., 2015). This is a more permanent sink for $\mathrm{NO}_{x}$ and would decrease the regeneration of $\mathrm{NO}_{x}$ from organic nitrates. While these studies have found evidence for hydrolysis of aerosol-phase organic nitrates $\left(\mathrm{ON}^{\mathrm{aer}}\right)$, it is not clear at which rate $\mathrm{ON}$ hydrolysis occurs. Correctly modeling organic nitrates and ozone formation depends on knowledge of the ON partitioning and hydrolysis rate.

While ON hydrolysis in the bulk phase has been studied for decades (Baker and Easty, 1950, 1952; Boschan et al., 1955), organic nitrate hydrolysis in atmospheric particles has only recently started to receive attention. Day et al. (2010) observed a decrease in particulate organic nitrates, measured in coastal southern California under acidic conditions at high relative humidity, and hypothesized hydrolysis as the cause. Browne et al. (2013) used ON hydrolysis to justify observations over the Boreal Forest of higher levels of $\mathrm{HNO}_{3}$ despite higher production rates of organic nitrates. The chamber ex- 
periments $(0$ to $>80 \% \mathrm{RH})$, performed by Liu et al. (2012) using trimethylbenzene (an anthropogenic volatile organic compound) and HONO as oxidant, were the first to measure the hydrolysis of condensed organic nitrates. Rindelaub et al. (2015) observed ON hydrolysis while measuring partitioning of $\alpha$-pinene SOA but did not directly quantify it. Boyd et al. (2015) measured hydrolysis of ON formed from nitrate radical oxidation of $\beta$-pinene.

The partitioning of organic nitrates to the particle phase is important to determine their fate as only condensed organic nitrates are expected to hydrolyze appreciably to $\mathrm{HNO}_{3}$. Absorptive partitioning theory (Pankow, 1994; Donahue et al., 2006; Rollins et al., 2013; Rindelaub et al., 2015) has been used to describe the gas-particle partitioning of organic nitrates. Rollins et al. (2013) used partitioning data from the 2010 CalNex campaign to find a volatility basis set distribution for ON observed at ambient aerosol concentrations. Rindelaub et al. (2015) observed the partitioning of organic nitrates formed from the $\cdot \mathrm{OH}$-initiated oxidation of $\alpha$-pinene at various levels of relative humidity. However, other work has suggested that the partitioning of organic nitrates to the particle phase is irreversible (Perraud et al., 2012). The goals of this work were to form organic nitrates in controlled environmental chamber experiments from the $\cdot \mathrm{OH}$-dominated oxidation of $\alpha$-pinene under high $\mathrm{NO}_{x}$ conditions and various relative humidity levels. Additionally, this work aimed to

- quantify the hydrolysis rate of organic nitrates

- verify whether the gas-particle partitioning of organic nitrates is reversible and can therefore be modeled by absorptive partitioning theory

- parameterize the gas-particle partitioning of organic nitrates.

\section{Methods}

\subsection{Environmental chamber experiments}

All experiments were performed in the atmospheric physicochemical processes laboratory experiments (APPLE) chamber located at the University of Texas at Austin (UT-Austin). The APPLE chamber is a $\sim 12 \mathrm{~m}^{3}$ Teflon ${ }^{\circledR}$ bag suspended inside of a temperature-controlled room. The walls of the room are lined with UV lights which can be used to induce photolysis reactions. The intensity of the UV lights has been characterized by the photolysis rate of $\mathrm{NO}_{2}$, which was measured to be $0.4 \mathrm{~min}^{-1}$, similar to ambient $\mathrm{NO}_{2}$ photolysis rates (e.g., $0.46 \mathrm{~min}^{-1}$ at a zenith angle of $40^{\circ}$, Carter et al., 2005). Before each experiment, the bag was flushed for at least $12 \mathrm{~h}$ with clean air from an Aadco clean air generator (model 737-14A) at a flow rate exceeding 100 liters per minute $\left(\mathrm{L} \mathrm{min}^{-1}\right)$. Ammonium sulfate $\left(\left(\mathrm{NH}_{4}\right)_{2} \mathrm{SO}_{4}\right)$ particles (Fisher Scientific, 99.5\%) were injected both to monitor wall-loss rates (Hildebrandt et al., 2009) as well as to act as seed particles onto which organic vapors can condense. Gas-phase NO was injected directly into the chamber from a cylinder (Airgas, $9.94 \mathrm{ppm} \pm 2 \%$ ) and liquid-phase $\alpha$-pinene (Sigma Aldrich, $98 \%$ ) was injected to a glass bulb and subsequently evaporated into the chamber with a steady stream of mildly heated air. $\mathrm{H}_{2} \mathrm{O}_{2}$, which photolyzes to $2 \cdot \mathrm{OH}$, was used as $\cdot \mathrm{OH}$ radical source and was injected either by bubbling air through an aqueous $\mathrm{H}_{2} \mathrm{O}_{2}$ solution (Fisher Scientific, $30 \%$ weight) or by injecting $\mathrm{H}_{2} \mathrm{O}_{2}$ solution into a glass bulb, and subsequently evaporated into the chamber with a steady stream of mildly heated air. Some experiments were performed under dry conditions ( $<5 \%$ relative humidity); in other experiments, humidity was increased by passing air through clean water and then into the chamber. Experimental conditions and results are summarized in Table 1. Results are discussed in Sect. 3.

Reactions were allowed to proceed for at least $4 \mathrm{~h}$ with continuous UV light. Experiments were run in a batch mode with no injections or dilution after the experiment was started; the bag volume of $12 \mathrm{~m}^{3}$ allowed ample time for sampling. In some cases, the temperature effects on gasparticle partitioning were observed by increasing temperature to $40^{\circ} \mathrm{C}$ in the chamber after the UV lights had been turned off (see Sect. 3.2).

\subsubsection{Instrumentation}

The composition of $\mathrm{PM}_{1}$ (particulate matter smaller than $1 \mu \mathrm{m}$ in diameter) was measured using an Aerosol Chemical Speciation Monitor (ACSM) from Aerodyne Research, Inc. (Ng et al., 2011). In the ACSM, particles are flash-vaporized on a heater at $600{ }^{\circ} \mathrm{C}$, and the resulting gas molecules are ionized using electron-impact ionization. This harsh ionization method results in fragmentation of most molecules. The molecular fragments, which are measured by a quadrupole mass spectrometer, are attributed to four categories - organics, nitrate, sulfate, and ammonium - using a fragmentation table (Allan et al., 2004). The instrument alternates between normal sampling and sampling through a particle filter, enabling subtraction of a gas-phase background. During this study the ACSM was operated at a time resolution (filter/sample-cycle length) of approximately $90 \mathrm{~s}$. The size distribution of particles was measured using a Scanning Electrical Mobility Spectrometer (SEMS) from Brechtel Manufacturing, Inc. The SEMS uses a Differential Mobility Analyzer (DMA) to size-select particles based on their electric mobility, which are then counted by a condensation particle counter (CPC). The DMA continuously cycled between the voltages which select particles ranging from 5 to $1000 \mathrm{~nm}$ in diameter, resulting in a time resolution of the particle size distribution of approximately $60 \mathrm{~s}$. 
Table 1. Experimental conditions and summary of results.

\begin{tabular}{|c|c|c|c|c|c|c|c|c|c|c|}
\hline Exp. & $\begin{array}{r}\text { Initial } \\
\alpha \text {-pinene } \\
(\mathrm{ppb})\end{array}$ & $\begin{array}{r}\text { Initial } \\
\text { NO (ppb) }\end{array}$ & $\begin{array}{l}\mathrm{RH} \\
(\%)\end{array}$ & $\begin{array}{r}\mathrm{H}_{2} \mathrm{O}_{2} \text { conc } \\
\text { in model } \\
(\mathrm{ppb})^{\mathrm{a}}\end{array}$ & $\begin{array}{r}\mathrm{O}_{3} \\
(\mathrm{ppb})^{\mathrm{b}}\end{array}$ & $\begin{array}{r}\mathrm{ON}^{\text {aer }} \\
\left(\mu \mathrm{g} \mathrm{m}^{-3}\right)^{\mathrm{b}, \mathrm{c}}\end{array}$ & $\begin{array}{r}\text { PM Org } \\
\left(\mu \mathrm{g} \mathrm{m}^{-3}\right)^{\mathrm{b}, \mathrm{c}}\end{array}$ & $\begin{array}{l}\mathrm{ON}^{\text {gas }} \\
(\mathrm{ppb})^{\mathrm{b}}\end{array}$ & $\begin{array}{r}\text { Part } \\
\text { coeff }^{d}\end{array}$ & $\begin{array}{r}\text { Hyd. } \\
\left(\text { day }^{-1}\right)\end{array}$ \\
\hline 1 & 40 & 30 & 22 & 100 & 90 & 7 & 90 & 13 & 0.19 & $\mathrm{NA}^{\mathrm{e}}$ \\
\hline 2 & 40 & 40 & 39 & 60 & 50 & 6 & 60 & 11 & 0.18 & 2.2 \\
\hline 3 & 40 & 40 & 0 & 40 & 50 & 4 & 30 & 13 & 0.10 & $\mathrm{NA}^{\mathrm{e}}$ \\
\hline 4 & 130 & 110 & 68 & 600 & 210 & & & & & 2.4 \\
\hline 5 & 130 & 130 & 22 & 900 & 330 & 70 & 780 & 57 & 0.33 & 1.8 \\
\hline 6 & 130 & 120 & 50 & 500 & 240 & 40 & 460 & 47 & 0.26 & 1.9 \\
\hline 7 & 130 & 120 & 15 & 200 & 210 & 50 & 510 & 34 & 0.38 & 0.2 \\
\hline 8 & 80 & 80 & 0 & 1000 & 300 & 30 & 310 & 32 & 0.26 & 0.6 \\
\hline 9 & 80 & 80 & 0 & 1500 & 330 & 20 & 270 & 28 & 0.25 & 0.2 \\
\hline 10 & 50 & 50 & 70 & 600 & 180 & & & & & 6.9 \\
\hline 11 & 40 & 40 & 70 & 200 & 70 & & & & & 2.5 \\
\hline 12 & 50 & 50 & 67 & 500 & 170 & & & & & 5.2 \\
\hline
\end{tabular}

${ }^{\mathrm{a}} \mathrm{H}_{2} \mathrm{O}_{2}$ concentration for which SAPRC model most closely matched measurements of $\mathrm{NO}_{x}$ and $\mathrm{O}_{3}$. ${ }^{\mathrm{b}}$ Measured and averaged over a 20 min period when PM organics peaked. ${ }^{\mathrm{c}}$ Corrected for wall losses as described in Sect. 2.1.2. ${ }^{\mathrm{d}}$ Molar basis. ${ }^{\mathrm{e}}$ Experimental conditions resulted in aerosol growth throughout the experiment.

Gas-phase reaction products were monitored using a highresolution time-of-flight chemical ionization mass spectrometer (HR-ToF-CIMS) from Aerodyne Research, Inc. The HR-ToF-CIMS uses softer chemical ionization which results in minimal fragmentation of parent molecules. Mass spectra are derived from measurements of the ions' time-of-flight as they are pulsed through a low pressure chamber in a "V" shape. Two chemical reagent ions were used: water clusters $\left(\mathrm{H}_{3} \mathrm{O}^{+} \cdot\left(\mathrm{H}_{2} \mathrm{O}\right)_{n}\right)$ and iodide-water clusters $\left(\mathrm{I}^{-} \cdot\left(\mathrm{H}_{2} \mathrm{O}\right)_{n}\right)$. Water cluster ionization is most sensitive towards detection of moderately oxidized hydrocarbons; the ability to ionize, and thus sensitivity, is based on the relative proton affinity between the water cluster and the parent molecule (Lindinger et al., 1998). This method was used to monitor $\alpha$-pinene as well as early-generation oxidation products. Iodide-water cluster ionization is most sensitive towards detection of more highly oxidized hydrocarbons; this method was used to observe later-generation oxidation products as well as $\mathrm{HNO}_{3}$ and $\mathrm{H}_{2} \mathrm{O}_{2}$. In the work presented here, data from the HRToF-CIMS are only used qualitatively since, as it was later discovered, a partially clogged inlet may have interfered with instrument calibration and quantitative measurements.

Concentrations of $\mathrm{NO}$ and $\mathrm{O}_{3}$ were measured using Teledyne chemiluminescence $\mathrm{NO}_{x}$ and absorption $\mathrm{O}_{3}$ monitors (200E and 400E, respectively); concentrations of $\mathrm{NO}_{2}$ were measured via an $\mathrm{NO}_{2}$ monitor from Environnement (Model AS32M), which uses a cavity attenuated phase shift (CAPS) method to directly measure $\mathrm{NO}_{2}$ (Kebabian et al., 2008). The advantage of this direct $\mathrm{NO}_{2}$ measurement is that it does not rely on $\mathrm{NO}_{2}$ conversion to $\mathrm{NO}$ and therefore does not suffer from interference by other oxidized nitrogen compounds, such as HONO and organic nitrates (Winer et al., 1973).

\subsubsection{Data analysis}

Data from the ACSM were analyzed in IGOR Pro (WaveMetrics) using the software package "ACSM Local," which includes a correction for relative ion transmission efficiency as well as changes in the flow rate throughout the experiment. The SEMS volume concentration was converted to mass using the densities $1.77 \mathrm{~g} \mathrm{~cm}^{-3}$ for ammonium sulfate and $1.4 \mathrm{~g} \mathrm{~cm}^{-3}$ for organics and organic nitrates $(\mathrm{Ng}$ et al., 2007). The time series of particle mass concentration (not corrected for wall losses) during Exp. 7 is shown in Fig. S1 in the Supplement; other experiments exhibited similar time series.

All PM nitrate was assumed to be organic because no inorganic nitrate was introduced in these controlled experiments. $\mathrm{PM}$ nitrate is measured by the ACSM as $\mathrm{NO}^{+}$and $\mathrm{NO}_{2}^{+}$ fragments, and the standard fragmentation table is used to estimate the portion of the $m / z 30$ that is due to $\mathrm{NO}^{+}$(as opposed to $\left({ }^{15} \mathrm{~N}\right)_{2}^{+}$or organics). Nitric acid is formed in the gas phase as well as in the particle phase through hydrolysis, but it is assumed that nitric acid concentrations are negligible in the particle phase due to its high vapor pressure (Fry et al., 2009). A Henry's law calculation suggests that the total amount of aqueous $\mathrm{HNO}_{3}$ in particles is 3 orders of magnitude lower than that in the gas phase.

The ACSM does not detect all sampled particles, primarily due to particle bounce at the vaporizer, resulting in a collection efficiency (CE) smaller than 1. Collection efficiency and wall losses were accounted for simultaneously by multiplying the ACSM concentrations of organics and organic nitrates by the mass concentration ratio $C_{\mathrm{SEMS}}^{t=0} / C_{\mathrm{ACSM}}^{\text {seed }}(t)$ as has been done in previous work (Hildebrandt et al., 2009). Here, $C_{\mathrm{SEMS}}^{t=0}$ is the mass concentration of ammonium sulfate seed just before the UV lights are turned on and organic 
aerosol formation commences, and $C_{\mathrm{ACSM}}^{\text {seed }}(t)$ is the time dependent mass concentration of $\left(\mathrm{NH}_{4}\right)_{2} \mathrm{SO}_{4}$ measured by the ACSM throughout the experiment. This correction assumes that particles on the chamber walls participate in gas-particle partitioning as though they are still in suspension, and that the suspended ammonium sulfate concentration changes only due to wall losses. It accounts for partitioning of organic vapors into wall-deposited particles (Hildebrandt et al., 2009) but does not account for losses of organic vapors onto the clean Teflon ${ }^{\circledR}$ walls (e.g., Matsunaga and Ziemann, 2010).

The ACSM standard fragmentation table was adjusted based on filter measurements taken in each experiment as described in the Supplement. Data from the HR-ToF-CIMS were analyzed in IGOR Pro (WaveMetrics) using Tofware, the software provided with the instrument. The data were first mass calibrated based on HR-ToF-CIMS reagent ions and other known ions. The baseline was subtracted and the average peak shape was found so it could be used for high resolution analysis, through which multiple ions can be identified at any given integer $m / z$. Ions up to $m / z 300$ were analyzed in high resolution mode. Only prominent ions were fit above $m / z 200$ because of the large number of possible ions at this high $m / z$. After ions were identified in the high resolution spectrum, the peaks were integrated to yield a time series of ions. Analyte ion concentrations were then normalized by the following reagent ion concentrations: the sum of $\mathrm{H}_{3} \mathrm{O}^{+}, \mathrm{H}_{3} \mathrm{O}^{+} \cdot\left(\mathrm{H}_{2} \mathrm{O}\right)$, and $\mathrm{H}_{3} \mathrm{O}^{+} \cdot\left(\mathrm{H}_{2} \mathrm{O}\right)_{2}$ for water cluster ionization and the sum of $\mathrm{I}^{-}$and $\mathrm{I}^{-} \cdot\left(\mathrm{H}_{2} \mathrm{O}\right)$ for iodide-cluster ionization. This correction accounts for changes in reagent ion concentrations and instrument sensitivity during and between experiments. Relative humidity can affect instrument sensitivity but this varied by less than $5 \%$ during each experiment.

The partitioning coefficient of a species is defined as the ratio of the species concentration in the particle phase to the total species concentration (gas and particle phase). For a single compound, the partitioning coefficient is the same whether it is on a mass or mole basis. However, for a mix of compounds, such as those formed in $\cdot \mathrm{OH}$-initiated oxidation, the mass and mole-basis partitioning coefficients will be different, with the coefficient expected higher on a mass basis since higher molecular weight compounds typically have lower vapor pressure. The partitioning coefficient in this work was calculated on a mole basis, in part because fragmentation in the ACSM makes it impossible to tell the original size and identity of ON molecules. This mole-basis partitioning coefficient is also more useful for most modeling efforts which group chemical species without knowledge of their exact molecular identity. The particle-phase ON concentration was quantified using data from the ACSM: the mass concentration of nitrate measured by the ACSM was converted to mixing ratio ( $\mathrm{ppb}$ ) using the molecular weight of the nitrate functional group $\left(62 \mathrm{~g} \mathrm{~mol}^{-1}\right)$. This assumes that the ON have only one nitrate functional group. Conversion of the nitrate mass concentration to mixing ratio avoids the need to assume an $\mathrm{ON}$ molecular weight (needed to estimate $\mathrm{ON}$ mass concentrations from ACSM) and is therefore deemed to be a more accurate measure of ON from the ACSM. Quantification of all gas-phase ON species would necessitate calibration and identification of all ON species, which is not feasible. Instead, a chamber box model and nitrogen balance was employed to estimate total gas-phase $\mathrm{ON}$ as described below.

\subsection{Chamber modeling and partitioning coefficient}

In these experiments only the following five major forms of oxidized nitrogen are present in significant concentrations: $\mathrm{NO}, \mathrm{NO}_{2}, \mathrm{HNO}_{3}, \mathrm{ON}^{\text {gas }}$, and $\mathrm{ON}^{\text {aer }}$ (gas and aerosol-phase organic nitrates, respectively). Figure S2 shows that, based on the Statewide Air Pollution Research Center (SAPRC) model (http://www.engr.ucr.edu/ carter/SAPRC/), the concentrations of other forms of reactive nitrogen are orders of magnitude lower than the concentrations of these five forms. Concentrations of $\mathrm{NO}$ and $\mathrm{NO}_{2}$ were measured using gas-phase monitors, $\mathrm{ON}^{\text {aer }}$ was measured using the ACSM, and concentrations of $\mathrm{HNO}_{3}$ were approximated using the SAPRC box model. The concentration of $\mathrm{ON}^{\text {gas }}$ was then calculated based on a nitrogen mass balance $\left(\mathrm{ON}^{\mathrm{gas}}=\mathrm{NO}_{x}^{\text {initial }}-\mathrm{NO}_{2}-\mathrm{NO}-\mathrm{ON}^{\text {aer }}-\mathrm{HNO}_{3}^{\text {model }}\right)$, and the partitioning coefficient was calculated as a time series for each experiment.

The concentration of $\mathrm{H}_{2} \mathrm{O}_{2}$ used in the model was adjusted until the modeled $\mathrm{NO}, \mathrm{NO}_{2}$, and $\mathrm{O}_{3}$ concentrations closely matched those measured throughout each experiment as shown in Fig. S3 for Exp. 7. In Exps. 1, 2, and 3 (which were used to calculate the volatility basis set parameters) $\mathrm{H}_{2} \mathrm{O}_{2}$ was injected by passing air through a solution of $\mathrm{H}_{2} \mathrm{O}_{2}$ and into the chamber, and the amount of $\mathrm{H}_{2} \mathrm{O}_{2}$ injected could not be estimated. In later experiments, $\mathrm{H}_{2} \mathrm{O}_{2}$ was directly injected into the chamber through evaporation of a known liquid volume of solution, and the estimated amount of $\mathrm{H}_{2} \mathrm{O}_{2}$ injected was about half of the $\mathrm{H}_{2} \mathrm{O}_{2}$ concentrations consistent with observed $\mathrm{NO}, \mathrm{NO}_{2}$, and $\mathrm{O}_{3}$ based on the model. This difference may be due to inefficient injection or uncertainties in the UV spectrum. The absorption cross section of $\mathrm{H}_{2} \mathrm{O}_{2}$ only minimally intersects with the emission spectrum of the UV lights used in this chamber. Thus, small changes in the UV spectrum (or errors in measurements of the spectrum) could cause significant errors in estimated concentrations of $\cdot \mathrm{OH}$, which drive the observed concentrations of $\mathrm{NO}, \mathrm{NO}_{2}$, and $\mathrm{O}_{3}$.

SAPRC simulations were conducted with the reaction mechanism Carbon Bond 6 revision 2 (CB6r2), which includes organic nitrate hydrolysis through a rate estimated from the work of Liu et al. (2012) and Rollins et al. (2013); updates to CB6r2 were described by Hildebrandt Ruiz and Yarwood (2013). Experiments were modeled with and without organic nitrate hydrolysis to see the effect on the predicted ON partitioning coefficient. The overall effect of this 
process was small, with a maximum effect being a $5 \%$ decrease to the partitioning coefficient by removing the hydrolysis mechanism from the model. This corresponded to a $17 \%$ decrease in $\mathrm{HNO}_{3}$, which suggests that the partitioning coefficient estimated in this work is not very sensitive to changes in the modeled $\mathrm{HNO}_{3}$ concentrations. For the results and analysis presented here, the $\mathrm{HNO}_{3}$ concentrations were taken from $\mathrm{CB} 6 \mathrm{r} 2$ with the inclusion of the $\mathrm{ON}$ hydrolysis process for experiments above $20 \% \mathrm{RH}$ and without the hydrolysis process for experiments below $20 \% \mathrm{RH}$.

According to absorptive partitioning theory (Pankow, 1994; Donahue et al., 2006), the gas-particle partitioning of an organic species depends on its vapor pressure and the concentration of organic material in the particle phase. The fraction of a compound $i$ in the particle phase $\left(Y_{i}\right)$ is given by (Donahue et al., 2006):

$Y_{i}=\left(1+\frac{C_{i}^{*}}{C_{\mathrm{OA}}}\right)^{-1}$

where $C_{\mathrm{OA}}$ is the organic aerosol concentration and $C_{i}^{*}$ is the saturation mass concentration of species $i$ (the saturation vapor pressure converted to concentration units). In the volatility basis set (VBS; Donahue et al., 2006), organic species are lumped by $C_{i}^{*}$ spaced logarithmically. This leads to an overall partitioning coefficient

$Y_{\mathrm{tot}}=\sum_{i=1}^{n} F_{i}\left(1+\frac{C_{i}^{*}}{C_{\mathrm{OA}}}\right)^{-1}$

(Rollins et al., 2013), where $F_{i}$ is the fraction of organic species in the volatility bin described by $C_{i}^{*}$. In this work we used measurements of $C_{\mathrm{OA}}$ and $Y_{\text {tot }}$ to fit the $F_{i}$ using a Matlab optimization routine. These VBS parameters can be used in models to represent the gas-particle partitioning of organic nitrates and account for changes in partitioning with temperature and $C_{\mathrm{OA}}$.

\section{Results and discussion}

A typical time series of compounds containing oxidized nitrogen is shown in Fig. 1 (Exp. 7). Initially the chamber contains only $\mathrm{NO}$ and a small amount of $\mathrm{NO}_{2}$, in addition to $\alpha$-pinene and inorganic seed aerosol. When the UV lights are activated at time $=0$, the NO immediately begins to react with $\cdot \mathrm{OH}$ and other radicals to form $\mathrm{NO}_{2}$ and additional $\mathrm{NO}_{y}$ compounds such as organic nitrates. Ozone formation also starts and thus in these experiments ozone also plays a role in the oxidation of $\alpha$-pinene. Based on the SAPRC model, $15 \%$ of the total $\alpha$-pinene reacts with ozone while the rest reacts with $\cdot \mathrm{OH}$. Table 1 summarizes results from all experiments. Concentrations of $\mathrm{O}_{3}, \mathrm{ON}^{\mathrm{aer}}$, PM organics, and $\mathrm{ON}^{\text {gas }}$ are averaged over approximately $20 \mathrm{~min}$ of the time when PM organics and nitrates peak in concentration. This

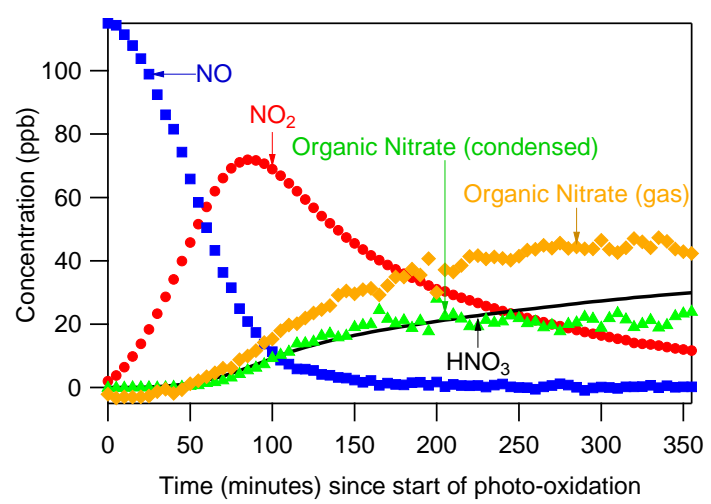

Figure 1. Time series of oxidized-nitrogen species in Exp. 7. NO, $\mathrm{NO}_{2}$, and organic nitrate (condensed) are measured directly. $\mathrm{HNO}_{3}$ is modeled using SAPRC. Organic nitrate (gas) is calculated from a mass balance.

averaging period was chosen so that experiments with different $\mathrm{H}_{2} \mathrm{O}_{2}$ concentrations could be compared even though they reach their maximum concentrations at different rates. Higher initial loading of $\mathrm{NO}_{x}, \alpha$-pinene, and $\mathrm{H}_{2} \mathrm{O}_{2}$ resulted in higher concentrations of ozone and PM.

Figure 2 shows time series of molecular ions identified using the HR-ToF-CIMS using water cluster ("positive mode") and iodide-water cluster ("negative mode") ionization. Many compounds are identified with the CIMS and a select few of the most prominent compounds were chosen for Fig. 2. In short time periods after switching reagent ions, the sensitivity of the HR-ToF-CIMS slowly adjusts to a steady state value. Minor changes during these short time periods should be taken with caution but the overall trends over the $4.5 \mathrm{~h}$ experiment are useful in viewing oxidation trends. The initial data collected in negative mode show that formation of organic nitrates begins immediately after oxidation has started. Later in the experiment, the less-oxygenated compounds observed in positive mode begin to decrease, while the more highly oxygenated compounds observed in negative mode continue to increase, consistent with oxidation and conversion of less-oxidized compounds to more highly oxidized compounds continuing throughout the experiment. Highly oxidized compounds which still contain ten carbon atoms (as the precursor $\alpha$-pinene) begin to decrease towards the end of the experiment while fragmented compounds (containing less than 10 carbon atoms) continue to increase, consistent with fragmentation of the carbon backbone during oxidation. Molecular weights of the gas-phase compounds identified here range from 221 to $279 \mathrm{~g} \mathrm{~mol}^{-1}$ and align well with the range of molecular weights estimated by Fry et al. (2009) for particle-phase organic nitrates formed from $\mathrm{NO}_{3}$ oxidation of $\beta$-pinene ( $229 \pm 12$ to $434 \pm 25 \mathrm{~g} \mathrm{~mol}^{-1}$ ). Gas-phase organic nitrates identified here are therefore expected to be semivolatile and to partition significantly to the particle phase. 


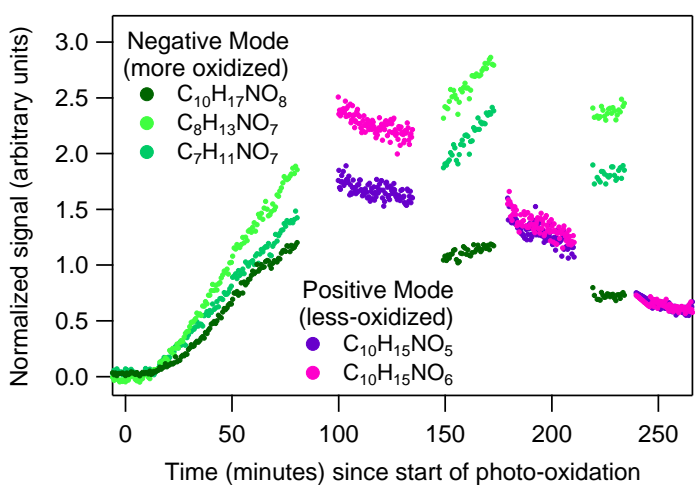

Figure 2. Time series of selected organic nitrates identified by HRToF-CIMS (Exp. 10).

\subsection{Hydrolysis of organic nitrates}

Concentrations of wall-loss-corrected (normalized to sulfate) PM nitrate were observed to decrease at the end of most experiments. These decreases of PM nitrate are attributed to physical or chemical processes in the gas and aerosol phases, and an exponential decay was fit to the data to quantify the decay. The exception was experiments 1 and 3 during which production of SOA was slow (primarily due to lower initial $\mathrm{H}_{2} \mathrm{O}_{2}$ and $\alpha$-pinene) and continued throughout the experiment, so a decay could not be observed. Examples of the decay for a humid and dry experiment are shown in Fig. S4. The decay rates for each experiment are reported in Table 1 and appear to depend on relative humidity as shown in Fig. 3. When the RH ranged between 20 and $60 \%$, an ON decay rate of $2 \mathrm{day}^{-1}$ was observed; no significant ON decay was observed at RH lower than $20 \%$. Experiments conducted at an average RH of $67 \%$ or higher can exhibit a significantly higher decay rate, probably due to effects of being near the deliquescence relative humidity of the ammonium sulfate seed aerosol. In Exps. 10 and 12, which have decay rates well above $2 \mathrm{day}^{-1}$, the chamber was initially cooled to $20^{\circ} \mathrm{C}$ before the UV lights were turned on. Once the UV lights were activated, the temperature then increased to $25^{\circ} \mathrm{C}$ and the RH settled at the values indicated in Table 1. For these experiments the $\mathrm{RH}$ was above $80 \%$ (the deliquescence $\mathrm{RH}-\mathrm{DRH})$ of $\left(\mathrm{NH}_{4}\right)_{2} \mathrm{SO}_{4}$ for several minutes, potentially resulting in aqueous aerosol. Experiment 11 also reached a relative humidity above deliquescence, yet it shows a lower nitrate loss rate than Exps. 10 and 12. The ratio of organics and nitrates to sulfate (seed) particles was much lower in Exp. 11 compared to Exps. 10 and 12, but whether and why this would result in a different nitrate loss rate is currently unclear. The relative humidity in Exp. 4 did not reach the DRH of $\left(\mathrm{NH}_{4}\right)_{2} \mathrm{SO}_{4}$. Future work should focus on the fate of $\mathrm{ON}$ at higher $(>60 \%)$ relative humidity. The generally higher nitrate loss rate at higher RH makes hydrolysis of particulate nitrate functional groups the most plausible explanation for the observed decay.

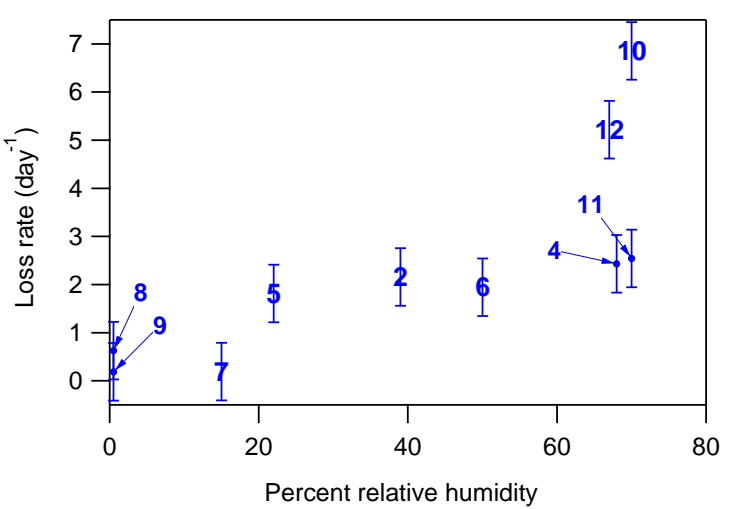

Figure 3. The organic nitrate loss rate as a function of relative humidity for Exps. 2, 4-12. Uncertainty (error bars) is estimated as 0.6 day $^{-1}$, the highest loss rate observed in experiments below $5 \%$ RH (Exp. 8).

PM organics also decreased in some experiments, but their loss rate was lower and more variable than that of nitrate. Based on the work by Chuang et al. (2015) the addition of a nitrate functional group decreases volatility of a compound by 2.5 orders of magnitude - slightly more than the substituted alcohol group from hydrolysis. Thus, the organic compound resulting from $\mathrm{ON}$ is more volatile than the original organic nitrate, and as a result could partition to the gas phase, resulting in a decrease in PM organics.

No direct observation of hydrolysis (conversion of the $-\mathrm{ONO}_{2}$ group to an $-\mathrm{OH}$ group) has been made in this or previous work. The estimated hydrolysis lifetime of $12 \mathrm{~h}$ (loss rate of $2 \mathrm{day}^{-1}$ ) for particulate organic nitrates is similar to hydrolysis rates suggested by other studies under humid conditions. Liu et al. (2012) observed a trend similar to that shown in Fig. 3 in chamber experiments in which ON were formed from the oxidation of tri-methyl benzene using $\mathrm{HONO}$ as the $\cdot \mathrm{OH}$ and $\mathrm{NO}_{x}$ source. In those experiments, PM nitrate was found to have a negligible loss rate below $20 \% \mathrm{RH}$ but a lifetime of $6 \mathrm{~h}$ at $40 \% \mathrm{RH}$ and higher. Perring et al. (2009) estimated the lifetime of isoprene nitrates to be between $95 \mathrm{~min}$ and $16 \mathrm{~h}$ depending on their branching ratio in isoprene $\cdot \mathrm{OH}$ oxidation. Boyd et al. (2015) measured a lifetime of $3-4.5 \mathrm{~h}$ for $10 \%$ of $\mathrm{ON}$ formed from $\mathrm{NO}_{3}$ oxidation of $\beta$-pinene, with a much longer lifetime for the remaining $90 \%$. This suggests that $10 \%$ of the ON functional groups were tertiary with the rest being primary or secondary, as those have been shown to hydrolyze much slower in the bulk phase (Darer et al., 2011; Hu et al., 2011). More tertiary ON groups are expected from $\alpha$-pinene than $\beta$-pinene, based on the location of the double bond.

Similar VOC precursors such as $\alpha$-pinene and $\beta$-pinene can form different fractions of primary/secondary and tertiary ON. When $\mathrm{NO}_{3}$ reacts and bonds with the terminal double bond of $\beta$-pinene, an alkyl radical is formed in either a primary or tertiary position (opposite of the carbon-nitrate 
bond). The tertiary alkyl radical is more stable, so primary organic nitrates are expected to be more abundant. The double bond in $\alpha$-pinene is not terminal, so the $\mathrm{NO}_{3}$ reaction produces either a secondary or tertiary $\mathrm{ON}$ and alkyl radical. $\mathrm{NO}_{3}$ typically bonds with the less-substituted carbon of a double bond so that a more highly substituted alkyl radical is formed. The reverse is true for $\mathrm{OH}+\mathrm{NO}$ chemistry. In this case NO reacts with the peroxy radical to form the nitrate group. The peroxy radical, a product of $\mathrm{O}_{2}$ and an alkyl radical, is likely to be on a more substituted carbon as this would have been the more stable alkyl radical. Thus, more highly substituted $\mathrm{ON}$ are expected from $\mathrm{OH}+\mathrm{NO}_{x}$ than from $\mathrm{NO}_{3}$ chemistry. This has important implications for attempts to model $\mathrm{ON}$ and the resulting $\mathrm{NO}_{x}$ recycling.

As Table 1 shows, experiments were conducted at varying $\mathrm{NO}_{x}$ and $\alpha$-pinene concentrations, relative humidity, and hydrogen peroxide $(\cdot \mathrm{OH}$ radical source) levels, which resulted in different final concentrations of PM nitrate and total OA. Liu et al. (2012) suggested that a lower PM nitrate / OA ratio at higher RH could be due to ON hydrolysis. In these experiments, the correlation between the ratio of PM nitrate / total $\mathrm{OA}$ (measured when total OA was highest) and RH was very low $\left(R^{2}=0.02\right)$. Thus, based on these experiments, differences in the observed final PM nitrate / OA are due to experimental conditions other than relative humidity.

\subsection{Gas-particle partitioning of organic nitrates}

In order to test the reversibility of ON partitioning, the temperature of the chamber was increased after OA had formed (and when the UV lights were off) in some experiments. Figure 4 shows gas- and particle-phase measurements taken from a representative experiment (Exp. 2). After the UV lights are turned off, there is a $60 \mathrm{~min}$ period in which the temperature stabilizes around $15^{\circ} \mathrm{C}$. This is followed by $\sim 90 \mathrm{~min}$ of heating to a final temperature of $45^{\circ} \mathrm{C}$. After this, the chamber is quickly cooled back to $15^{\circ} \mathrm{C}$. Figure $4 \mathrm{~b}$ shows a time series of the organics / sulfate and nitrate / sulfate mass ratios measured by the ACSM. Sulfate has a low vapor pressure and does not evaporate significantly at the temperatures investigated; therefore changes in the nitrate / sulfate and organics / sulfate ratios with chamber temperature can be attributed to partitioning of organic nitrates and other organic species between the gas and particle phases or wall losses of gas-phase species. As Fig. 4b shows, organics / sulfate and nitrate / sulfate decreased with increasing temperature and increased with decreasing temperature, suggesting evaporation of species at higher temperatures and their repartitioning to the particle phase at lower temperatures.

Figure $4 \mathrm{c}$ shows the effects of temperature on various compounds measured in the gas phase. Several organic compounds - with and without $\mathrm{ON}$ functional groups - increase with increasing temperature. This suggests that these compounds are present in both the gas and particle phases and

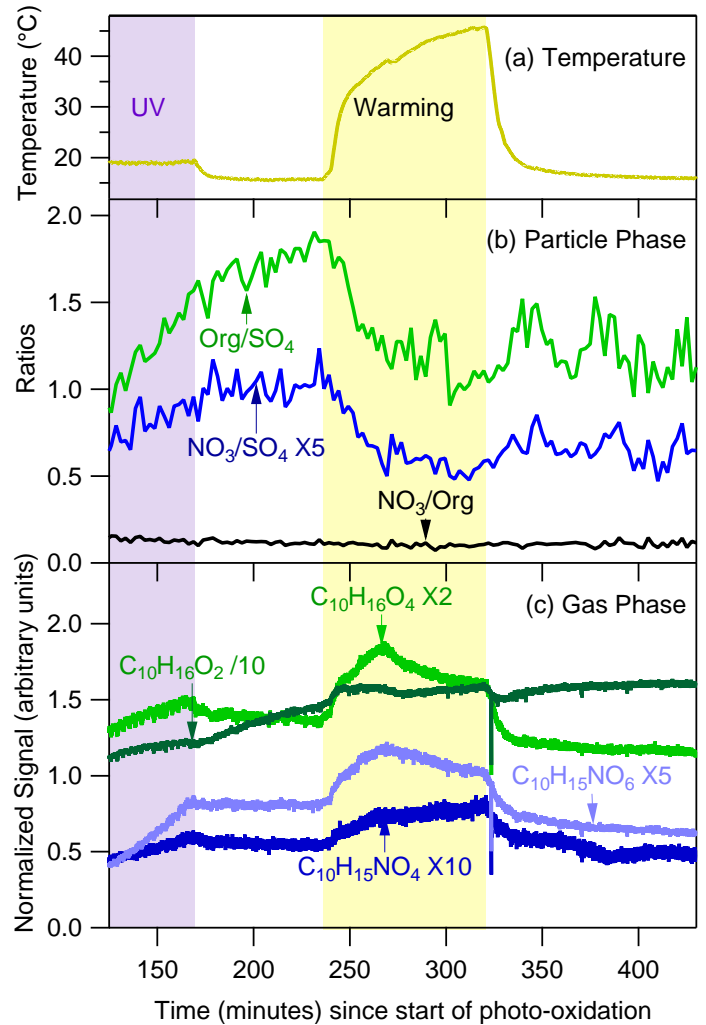

Figure 4. Temperature effects on gas-particle partitioning (Exp. 2). Organics, nitrate, and sulfate are abbreviated as $\mathrm{Org}, \mathrm{NO}_{3}$, and $\mathrm{SO}_{4}$, respectively.

evaporate at higher temperature resulting in increased gasphase concentrations. As temperature is increased the percent change in the concentration of gas-phase $\mathrm{C}_{10} \mathrm{H}_{16} \mathrm{O}_{2}$ is less than the change in $\mathrm{C}_{10} \mathrm{H}_{16} \mathrm{O}_{4}$ and the percent change in the concentration of gas-phase $\mathrm{C}_{10} \mathrm{H}_{15} \mathrm{NO}_{4}$ is less than the change in $\mathrm{C}_{10} \mathrm{H}_{15} \mathrm{NO}_{6}$. This is consistent with the more highly oxidized compounds having a lower vapor pressure and evaporating less. As the temperature is decreased back to $15^{\circ} \mathrm{C}$, the concentrations return to the pre-heating trends, suggesting that recondensation to the particle phase has occurred. These observations, as well as the trends seen in particle-phase measurements, are consistent with equilibrium partitioning and inconsistent with the irreversible partitioning of ON recently suggested by Perraud et al. (2012).

Other processes may influence particle and gas concentrations of organic compounds. Continuing reactions with $\mathrm{O}_{3}$ and nitrate radicals (since $\mathrm{O}_{3}$ and $\mathrm{NO}_{2}$ are both present) limit the ability to stop all chemical activity. This is seen in the gas-phase compounds, some of which appear to be changing in concentration after the UV lights are off. Despite this, a clear change is seen in all compounds with a temperature increase. During the cooling phase (beginning at $t=320 \mathrm{~min}$ ) the particle-phase organic and nitrate concentrations do not return to the original levels. It is likely that some organic 
compounds are lost to the walls of the Teflon chamber, especially since they reach the coldest temperatures during active cooling, and thus organics / sulfate does not return to the values seen before temperature changes began. Despite these limitations, it is clear that both the organics / sulfate and nitrate / sulfate ratios decrease with heating, consistent with semivolatile organics and organic nitrates.

Table 1 summarizes the ON partitioning coefficient averaged over approximately $20 \mathrm{~min}$ from when PM organics and nitrates peak in concentration. PM concentration and partitioning data are not calculated for experiments above $60 \%$ RH. As discussed, these experiments had higher and less consistent nitrate decay rates which may affect partitioning. There may also be issues in applying the wall loss and CE corrections used here and in previous work (Hildebrandt et al., 2009), which assume that the particles measured by the SEMS before the UV lights are turned on consist only of ammonium sulfate. In these high RH experiments, the particles may contain a significant fraction of water. The wall loss correction also assumes that particles lost to the walls participate in partitioning as though they were still in suspension. This assumption may be poor if small amounts of water condense onto the walls of the chamber in these high RH experiments.

Data taken throughout the lower-concentration experiments (Exps. 1, 2, and 3) with UV lights on, were fit to a volatility basis set as these experiments were conducted under conditions which are more atmospherically relevant. VBS parameters are static but are often used to approximate dynamic systems such as the one observed in these experiments. Experimental data were used after total PM organics (corrected for wall losses) had reached $2 \mu \mathrm{g} \mathrm{m}^{-3}$ to avoid effects of noise and model uncertainty at the beginning of the experiments when concentrations of both gas- and particlephase organic nitrates were low. Outlying points (for example, when PM organics temporarily rose above $2 \mu \mathrm{g} \mathrm{m}{ }^{-3}$ but subsequent data suggested that condensation had not begun) were removed as well. Figure 5 shows the data used to find the volatility basis set along with the fit. The $C^{*}$ values used for this were $1,10,100$, and $1000 \mu \mathrm{g} \mathrm{m}^{-3}$; the corresponding mass fractions $\left(F_{i}\right)$ calculated to give the best fit for Eq. (2) (Sect. 2.2) are $F_{i}=0,0.11,0.03$, and 0.86 .

As seen in Fig. 5, these results indicate that, under typical ambient conditions ( $<40 \mu \mathrm{g} \mathrm{m}^{-3}$ of OA), $5-10 \%$ of organic nitrates formed from the photo-oxidation of $\alpha$-pinene under high $\mathrm{NO}_{x}$ conditions are expected to partition to the particle phase. This is significantly lower than the organic nitrate partitioning calculated by Rollins et al. (2013) for organic nitrates measured in Bakersfield, CA during the CalNex campaign in 2010. In those measurements $>30 \%$ partitioning of ON was observed at organic aerosol concentrations of $10 \mu \mathrm{g} \mathrm{m}^{-3}$. The difference could be attributed to differences in precursor molecules and levels of oxidation. Studies have shown that high $\mathrm{NO}_{x}$ conditions can shift photochemical oxidation products of terpenes towards higher volatility compounds (Wildt et al. 2014). Rollins et al. determined using the

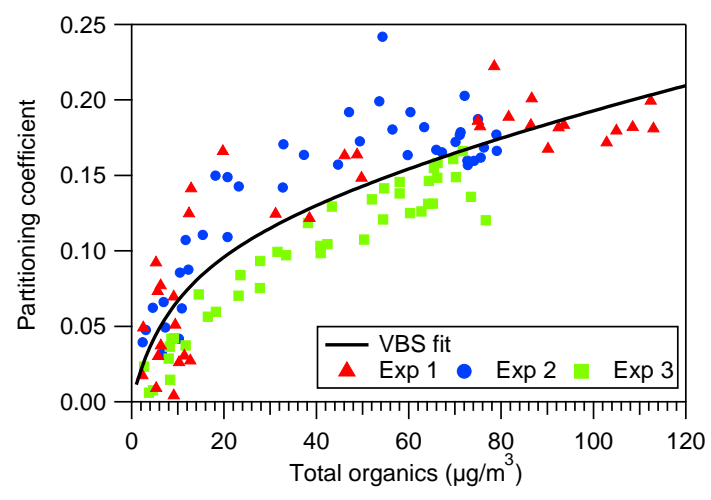

Figure 5. Volatility basis set fit from this work shown with data from Exps. 1, 2, and 3.

SPARC model (Hilal et al., 2003) that precursor molecules (a mix of C5-C15 VOCs) would need two stages of oxidative chemistry beyond the initial oxidation of the VOC to reach the point when 19-28\% would partition to the particle phase for a $C_{\mathrm{OA}}$ of $3 \mu \mathrm{g} \mathrm{m}^{-3}$. This may suggest that the $\mathrm{ON}$ formed in our experiments have undergone fewer than three generations of oxidation as they are more volatile than the ON measured in Bakersfield during CalNex 2010. It should also be noted that the thermal-dissociation laser-induced fluorescence (TD-LIF) instrument used by Rollins et al. (2013) has been shown in a recent study to measure PM ON as a factor of 2 higher than the ON measured by aerosol mass spectrometers (Ayres et al., 2015) which utilize similar measurement and detection techniques as the ACSM used in this work. While the reasons for this difference are unknown, it would result in a higher partitioning coefficient compared to the one calculated from the AMS (or ACSM) and explain part of the observed difference.

\section{Conclusions}

Organic nitrates formed during the oxidation of $\alpha$-pinene decay in the particle phase at a rate of 2 day $^{-1}$ when RH is between 20 and $60 \%$; no significant decay is observed below $20 \% \mathrm{RH}$. During experiments when the highest observed RH exceeded the deliquescence $\mathrm{RH}$ of the ammonium sulfate seed aerosol, the particle-phase ON decay was as high as 7 day $^{-1}$ and more variable. The dependence of observed decay rate on relative humidity suggests organic nitrate hydrolysis as the most plausible explanation. The gas-particle partitioning of ON determines their potential to hydrolyze. Partitioning of the $\mathrm{ON}$ is reversible and can be described by a volatility basis set.

The conversion of $\mathrm{NO}_{x}$ to organic nitrates affects local ozone production. Partitioning and hydrolysis of organic nitrates affect regional concentrations of organic particulate matter and ozone. The organic nitrate partitioning coefficient and hydrolysis rates from this work can be used to include 
these processes in chemical transport models and more accurately represent the effect of organic nitrates on concentrations of ozone and particulate matter.

\section{The Supplement related to this article is available online at doi:10.5194/acp-16-2175-2016-supplement.}

Acknowledgements. This work was funded in part through a grant from the Texas Commission on Environmental Quality (TCEQ), administered by The University of Texas through the Air Quality Research Program (Project 12-012). The contents, findings, opinions, and conclusions are the work of the authors and do not necessarily represent findings, opinions, or conclusions of the TCEQ. The work was also funded in part with funds from the State of Texas as part of the program of the Texas Air Research Center. The contents do not necessarily reflect the views and policies of the sponsor nor does the mention of trade names or commercial products constitute endorsement or recommendation for use.

Edited by: S. A. Nizkorodov

\section{References}

Allan, J. D., Delia, A. E., Coe, H., Bower, K. N., Alfarra, M. R., Jimenez, J. L., Middlebrook, A. M., Drewnick, F., Onasch, T. B., Canagaratna, M. R., Jayne, J. T., and Worsnop, D. R.: A generalised method for the extraction of chemically resolved mass spectra from Aerodyne aerosol mass spectrometer data, J. Aerosol Sci., 35, 909-922, doi:10.1016/j.jaerosci.2004.02.007, 2004.

Ayres, B. R., Allen, H. M., Draper, D. C., Brown, S. S., Wild, R. J., Jimenez, J. L., Day, D. A., Campuzano-Jost, P., Hu, W., de Gouw, J., Koss, A., Cohen, R. C., Duffey, K. C., Romer, P., Baumann, K., Edgerton, E., Takahama, S., Thornton, J. A., Lee, B. H., Lopez-Hilfiker, F. D., Mohr, C., Wennberg, P. O., Nguyen, T. B., Teng, A., Goldstein, A. H., Olson, K., and Fry, J. L.: Organic nitrate aerosol formation via $\mathrm{NO}_{3}+$ biogenic volatile organic compounds in the southeastern United States, Atmos. Chem. Phys., 15, 13377-13392, doi:10.5194/acp-15-13377-2015, 2015.

Baker, J. and Easty, D.: Hydrolysis of Organic Nitrates, Nature, 166, 156-156, doi:10.1038/166156a0, 1950.

Baker, J. and Easty, D.: Hydrolylic Decomposition of Esters of Nitric Acid .1. General Experimental Techniques - Alkaline Hydrolysis and Neutral Solvolysis of Methyl, Ethyl, Isopropyl, and Tert-Butyl Nitrates in Aqueous Alcohol, J. Chem. Soc., 1952, 1193-1207, doi:10.1039/jr9520001193, 1952.

Boschan, R., Merrow, R. T., and Van Dolah, R. W.: The Chemistry of Nitrate Esters, Chem. Rev., 55, 485-510, doi:10.1021/cr50003a001, 1955.

Boyd, C. M., Sanchez, J., Xu, L., Eugene, A. J., Nah, T., Tuet, W. Y., Guzman, M. I., and Ng, N. L.: Secondary organic aerosol formation from the $\beta$-pinene $+\mathrm{NO}_{3}$ system: effect of humidity and peroxy radical fate, Atmos. Chem. Phys., 15, 7497-7522, doi:10.5194/acp-15-7497-2015, 2015.
Browne, E. C., Min, K.-E., Wooldridge, P. J., Apel, E., Blake, D. R., Brune, W. H., Cantrell, C. A., Cubison, M. J., Diskin, G. S., Jimenez, J. L., Weinheimer, A. J., Wennberg, P. O., Wisthaler, A. and Cohen, R. C.: Observations of total $\mathrm{RONO}_{2}$ over the boreal forest: $\mathrm{NO}_{x}$ sinks and $\mathrm{HNO}_{3}$ sources, Atmos. Chem. Phys., 13(9), 4543-4562, doi:10.5194/acp-13-4543-2013, 2013.

Carter, W., Cockeriii, D., Fitz, D., Malkina, I., Bumiller, K., Sauer, C., Pisano, J., Bufalino, C., and Song, C.: A new environmental chamber for evaluation of gas-phase chemical mechanisms and secondary aerosol formation, Atmos. Environ., 39, 7768-7788, doi:10.1016/j.atmosenv.2005.08.040, 2005.

Chuang, W. K. and Donahue, N. M.: A two-dimensional volatility basis set - Part 3: Prognostic modeling and $\mathrm{NO}_{x}$ dependence, Atmos. Chem. Phys., 16, 123-134, doi:10.5194/acp-16-123-2016, 2016.

Darer, A. I., Cole-Filipiak, N. C., O'Connor, A. E., and Elrod, M. J.: Formation and stability of atmospherically relevant isoprenederived organosulfates and organonitrates., Environ. Sci. Technol., 45, 1895-902, doi:10.1021/es103797z, 2011.

Day, D. A., Liu, S., Russell, L. M., and Ziemann, P. J.: Organonitrate group concentrations in submicron particles with high nitrate and organic fractions in coastal southern California, Atmos. Environ., 44, 1970-1979, doi:10.1016/j.atmosenv.2010.02.045, 2010.

Donahue, N. M., Robinson, A. L., Stanier, C. O., and Pandis, S. N.: Coupled partitioning, dilution, and chemical aging of semivolatile organics., Environ. Sci. Technol., 40, 2635-2643, doi:10.1021/es052297c, 2006.

Fry, J. L., Kiendler-Scharr, A., Rollins, A. W., Wooldridge, P. J., Brown, S. S., Fuchs, H., Dubé, W., Mensah, A., dal Maso, M., Tillmann, R., Dorn, H.-P., Brauers, T., and Cohen, R. C.: Organic nitrate and secondary organic aerosol yield from $\mathrm{NO}_{3}$ oxidation of $\beta$-pinene evaluated using a gas-phase kinetics/aerosol partitioning model, Atmos. Chem. Phys., 9, 14311449, doi:10.5194/acp-9-1431-2009, 2009.

Hilal, S., Karickhoff, S., and Carreira, L.: Prediction of the vapor pressure boiling point, heat of vaporization and diffusion coefficient of organic compounds, QSAR Comb. Sci., 22, 565-574, doi:10.1002/qsar.200330812, 2003.

Hildebrandt, L., Donahue, N. M., and Pandis, S. N.: High formation of secondary organic aerosol from the photo-oxidation of toluene, Atmos. Chem. Phys., 9, 2973-2986, doi:10.5194/acp-92973-2009, 2009.

Hildebrandt Ruiz, L. and Yarwood, G.: Interactions between Organic Aerosol and NOy, Austin, TX. Prepared for the Texas AQRP (Project 12-012), by the University of Texas at Austin, and ENVIRON International Corporation, Novato, CA, available at: http://aqrp.ceer.utexas.edu/projectinfoFY12_13/12-012/ 12-012FinalReport.pdf (last access: 24 July 2014), 2013.

Hu, K. S., Darer, A. I., and Elrod, M. J.: Thermodynamics and kinetics of the hydrolysis of atmospherically relevant organonitrates and organosulfates, Atmos. Chem. Phys., 11, 8307-8320, doi:10.5194/acp-11-8307-2011, 2011.

Jacobs, M. I., Burke, W. J., and Elrod, M. J.: Kinetics of the reactions of isoprene-derived hydroxynitrates: gas phase epoxide formation and solution phase hydrolysis, Atmos. Chem. Phys., 14, 8933-8946, doi:10.5194/acp-14-8933-2014, 2014.

Kebabian, P. L., Wood, E. C., Herndon, S. C., and Freedman, A.: A practical alternative to chemiluminescence-based detection of ni- 
trogen dioxide: Cavity attenuated phase shift spectroscopy, Environ. Sci. Technol., 42, 6040-6045, doi:10.1021/es703204j, 2008.

Lindinger, W., Hansel, A., Jordan, A., and Hansel, A.: Protontransfer-reaction mass spectrometry (PTR-MS): on-line monitoring of volatile organic compounds at pptv levels, Chem. Soc. Rev., 27, 347-354, 1998.

Liu, S., Shilling, J. E., Song, C., Hiranuma, N., Zaveri, R. A., and Russell, L. M.: Hydrolysis of Organonitrate Functional Groups in Aerosol Particles, Aerosol Sci. Tech., 46, 1359-1369, doi:10.1080/02786826.2012.716175, 2012.

Matsunaga, A. and Ziemann, P. J.: Gas-Wall Partitioning of Organic Compounds in a Teflon Film Chamber and Potential Effects on Reaction Product and Aerosol Yield Measurements, Aerosol Sci. Tech., 44, 881-892, doi:10.1080/02786826.2010.501044, 2010.

Ng, N. L., Chhabra, P. S., Chan, A. W. H., Surratt, J. D., Kroll, J. H., Kwan, A. J., McCabe, D. C., Wennberg, P. O., Sorooshian, A., Murphy, S. M., Dalleska, N. F., Flagan, R. C., and Seinfeld, J. H.: Effect of NOx level on secondary organic aerosol (SOA) formation from the photooxidation of terpenes, Atmos. Chem. Phys., 7, 5159-5174, doi:10.5194/acp-7-5159-2007, 2007.

Ng, N. L., Herndon, S. C., Trimborn, A., Canagaratna, M. R., Croteau, P. L., Onasch, T. B., Sueper, D., Worsnop, D. R., Zhang, Q., Sun, Y. L., and Jayne, J. T.: An Aerosol Chemical Speciation Monitor (ACSM) for Routine Monitoring of the Composition and Mass Concentrations of Ambient Aerosol, Aerosol Sci. Tech., 45, 780-794, doi:10.1080/02786826.2011.560211, 2011.

Pankow, J. F.: An absorption model of gas/particle partitioning of organic compounds in the atmosphere, Atmos. Environ., 28, 185-188, doi:10.1016/1352-2310(94)90093-0, 1994.

Perraud, V., Bruns, E. a, Ezell, M. J., Johnson, S. N., Yu, Y., Alexander, M. L., Zelenyuk, A., Imre, D., Chang, W. L., Dabdub, D., Pankow, J. F., and Finlayson-Pitts, B. J.: Nonequilibrium atmospheric secondary organic aerosol formation and growth, P. Natl. Acad. Sci. USA, 109, 2836-2841, doi:10.1073/pnas.1119909109, 2012.
Perring, A. E., Bertram, T. H., Wooldridge, P. J., Fried, A., Heikes, B. G., Dibb, J., Crounse, J. D., Wennberg, P. O., Blake, N. J., Blake, D. R., Brune, W. H., Singh, H. B., and Cohen, R. C.: Airborne observations of total $\mathrm{RONO}_{2}$ : new constraints on the yield and lifetime of isoprene nitrates, Atmos. Chem. Phys., 9, 14511463, doi:10.5194/acp-9-1451-2009, 2009.

Rindelaub, J. D., McAvey, K. M., and Shepson, P. B.: The photochemical production of organic nitrates from $\alpha$-pinene and loss via acid-dependent particle phase hydrolysis, Atmos. Environ., 100, 193-201, doi:10.1016/j.atmosenv.2014.11.010, 2015.

Rollins, A. W., Pusede, S., Wooldridge, P., Min, K.-E., Gentner, D. R., Goldstein, A. H., Liu, S., Day, D. A., Russell, L. M., Rubitschun, C. L., Surratt, J. D., and Cohen, R. C.: Gas/particle partitioning of total alkyl nitrates observed with TDLIF in Bakersfield, J. Geophys. Res.-Atmos., 118, 6651-6662, doi:10.1002/jgrd.50522, 2013.

Seinfeld, J. H. and Pandis, S. N.: Atmospheric Chemistry and Physics, 2nd Edn., Wiley-Interscience, Hoboken, 2006.

Yarwood, G., Heo, G., Carter, W. P. L., and Whitten, G. Z.: Environmental Chamber Experiments to Evaluate $\mathrm{NO}_{x}$ Sinks and Recycling in Atmospheric Chemical Mechanisms AQRP Project 10-042, available at: http://aqrp.ceer.utexas.edu/projectinfo \% 5C10-042\%5C10-042FinalReport.pdf, last access: 17 December 2012.

Wildt, J., Mentel, T. F., Kiendler-Scharr, A., Hoffmann, T., Andres, S., Ehn, M., Kleist, E., Müsgen, P., Rohrer, F., Rudich, Y., Springer, M., Tillmann, R., and Wahner, A.: Suppression of new particle formation from monoterpene oxidation by $\mathrm{NO}_{x}$, Atmos. Chem. Phys., 14, 2789-2804, doi:10.5194/acp-14-27892014, 2014.

Winer, A. M., Peters, J. W., Smith, J. P., and Pitts, J. N.: Response of Commercial Chemiluminescent NO-NO, Analyzers to Other Nitrogen-Containing Compounds, Environ. Sci. Technol., 8, 1118-1121, doi:10.1021/es60098a004, 1973. 